\title{
Analisis Perhitungan Overall Equipment Effectiveness Guna Mengurangi Six Big Losses dan Upaya Perbaikan Dengan Pendekatan Kaizen 5S
}

\author{
Raden Roro Dian Rahayu N \\ Fakultas Teknik \\ Program Studi Teknik Industri \\ Universitas Langlangbuana \\ Radenrorodian5@gmail.com \\ Hennie Husniah \\ Fakultas Teknik \\ Program Studi Teknik Industri \\ Universitas Langlangbuana \\ hennie.husniah@gmail.com
}

\author{
Leni Herdiani \\ Fakultas Teknik \\ Program Studi Teknik Industri \\ Universitas Langlangbuana \\ leni.herdiani@gmail.com
}

\begin{abstract}
Abstrak - PT.KHSTEX saat ini sedang menghadapi kendala pada kualitas produk kain grey yang tidak sesuai dengan standar yang diharapkan. hal ini dapat berdampak buruk pada perusahaan sehingga akan menyebabkan ongkos produksi meningkat, keuntungan menurun, dan loyalitas pelangganpun ikut menurun apabila kualitas produk tidak diperhatikan oleh perusahaan. Dari perhitungan OEE tingkat efektivitas mesin palet menurut standart wordclass bisa dikatakan belum baik hal ini bisa dilihat dari perolehan nilai OEE dengan rata-rata persentase sebesar $71,8 \%$ dimana menurut standar word class dianggap efektif apabila berada diatas $85 \%$, artinya kinerja dari mesin palet pada bulan september belum maksimal. Jenis Six Big Losses yang dominan pada mesin palet yaitu defect losses dan reduced speed losses. defect losses memiliki nilai sebesar $11,49 \%$ dan persentase terhadap losses lain yaitu sebesar 84,29\%. Sedangkan reduce speed losses memiliki nilai sebesar $13,79 \%$ dan persentase terhadap losses lain sebesar $45,97 \%$.
\end{abstract}

Kata kunci - big six losses, Overall Equipment Effectiveness, defect, kaizen $5 S$.

\section{PENDAHULUAN}

Menurut (Hansen dan Mowen, 2001); (dalam Wahyuanti, 2014) produk cacat adalah produk yang tidak memenuhi spesifikasi dan tidak sesuai dengan standar kualitas yang telah ditetapkan.

Salah satu perkembangan metode yang sering digunakan merupakan total preventive maintenance (TPM). (Mobley, 2008) mendefinisikan TPM sebagai sebuah strategi pemeliharaan komprehensif yang didasarkan atas pendekatan daur hidup (life cycle) alat yang dapat meminimumkan terjadinya kerusakan pada peralatan, cacat produksi dan kecelakaan kerja. TPM melibatkan siapapun dalam organisasi, mulai dari top level management hingga ke teknisi. TPM menjadi alat ukur perusahaan dalam continuous improvement.

Penelitian ini akan melakukan kajian terhadap mesin palet. Penelitian dilakukan dengan perhitungan OEE (Overall Equipment Effectiveness). Perhitungan OEE akan melibatkan availability, performance dan quality. Ketiga jenis faktor tersebut dijabarkan dalam beberapa jenis kerugian, yaitu breakdown losses, set up and adjusment, reduce speed, dan process defect (Nakajima, 1988). Beradasarkan faktor tersebut dapat diketahui nilai OEE dan akan diketahui kerugian terbesar yang ditimbulkan oleh mesin palet. 


\section{METODE}

\subsection{Overall Equipment Effectiveness (OEE)}

Usaha perbaikan pada industri manufaktur, dilihat dari segi peralatan, adalah dengan meningkatkan utilitas peralatan yang ada seoptimal mungkin dan memperpanjang umur ekonomisnya. Utilisasi dari peralatan pada rataan industri manufaktur adalah sekitar setengah dari kemampuan mesin yang sesungguhnya (Nakajima, 1988).

\subsection{Kaizen}

Kaizen adalah strategi untuk melakukan peningkatan secara terus menerus terhadap proses produksi, kualitas produk, efisiensi, dan keamanan kerja. Selain mengidentifikasi proses yang perlu di tingkatkan kaizen juga dapat melakukan evaluasi terhadap standard operating procedure (SOP) atau membuat SOP baru. Metode- metode yang digunakan dalam mengidentifikasi proyek kaizen antara lain metode DMAIC dan metode PDCA (plan, do, check, action).

\section{HASIL DAN DISKUSI}

\subsection{Overall Equipment Effectiveness (OEE)}

Setelah melakukan perhitungan Availability Rate, Performance Rate, dan Quality Rate, maka dapat mengetahui nilai Overall Equipment Effectiveness (OEE) dengan rumus sebagai berikut:

\section{OEE $=$ Availability $x$ Performance Rate $x$ Quality Rate $O E E=96,28 \% \times 81,17 \% x \quad 84,04 \%$ $O E E=65,68 \%$}

Dengan menggunakan rumus yang sama, maka pada tabel 4.8 diketahui nilai $O E E$ pada bulan september 2019 adalah sebagai berikut:

\begin{tabular}{|c|c|c|c|c|c|}
\hline NO & $\begin{array}{c}\text { Hari/Ta } \\
\text { nggal }\end{array}$ & $\begin{array}{l}\text { Ava } \\
\text { ilab } \\
\text { ility }\end{array}$ & $\begin{array}{c}\text { Perfor } \\
\text { mance } \\
\text { Time }\end{array}$ & $\begin{array}{c}\text { Quali } \\
\text { ty } \\
\text { Rate }\end{array}$ & OEE \\
\hline 1 & $\begin{array}{c}\text { 02-Sep- } \\
19\end{array}$ & $\begin{array}{c}0,96 \\
28\end{array}$ & 0,8117 & $\begin{array}{c}0,840 \\
41\end{array}$ & 65,68 \\
\hline 2 & $\begin{array}{c}\text { 03-Sep- } \\
19\end{array}$ & $\begin{array}{c}0,97 \\
47\end{array}$ & 0,7894 & $\begin{array}{c}0,847 \\
32\end{array}$ & 65,19 \\
\hline 3 & $\begin{array}{c}\text { 04-Sep- } \\
19\end{array}$ & $\begin{array}{c}0,95 \\
15\end{array}$ & 0,8419 & $\begin{array}{c}0,835 \\
28\end{array}$ & 66,91 \\
\hline 4 & $\begin{array}{c}\text { 05-Sep- } \\
19\end{array}$ & $\begin{array}{c}0,97 \\
47\end{array}$ & 0,8036 & $\begin{array}{c}0,862 \\
51\end{array}$ & 67,56 \\
\hline 5 & $\begin{array}{c}\text { 06-Sep- } \\
19\end{array}$ & $\begin{array}{c}0,97 \\
30 \\
\end{array}$ & 0,7965 & $\begin{array}{c}0,866 \\
19\end{array}$ & 67,13 \\
\hline 6 & $\begin{array}{c}\text { 09-Sep- } \\
19 \\
\end{array}$ & $\begin{array}{c}0,97 \\
22 \\
\end{array}$ & 0,8114 & $\begin{array}{c}0,870 \\
68 \\
\end{array}$ & 68,69 \\
\hline 7 & $\begin{array}{c}\text { 10-Sep- } \\
19\end{array}$ & $\begin{array}{c}0,95 \\
86\end{array}$ & 0,8408 & $\begin{array}{c}0,868 \\
28\end{array}$ & 69,98 \\
\hline 8 & $\begin{array}{c}\text { 11-Sep- } \\
19\end{array}$ & $\begin{array}{c}0,97 \\
76\end{array}$ & 0,8706 & $\begin{array}{c}0,872 \\
87\end{array}$ & 74,29 \\
\hline 9 & $\begin{array}{c}\text { 12-Sep- } \\
19\end{array}$ & $\begin{array}{c}0,97 \\
22\end{array}$ & 0,8513 & $\begin{array}{c}0,871 \\
52\end{array}$ & 72,13 \\
\hline 10 & $\begin{array}{c}\text { 13-Sep- } \\
19\end{array}$ & $\begin{array}{c}0,98 \\
58\end{array}$ & 0,7992 & $\begin{array}{c}0,852 \\
51\end{array}$ & 67,16 \\
\hline 11 & $\begin{array}{c}\text { 16-Sep- } \\
19\end{array}$ & $\begin{array}{c}0,96 \\
30\end{array}$ & 0,8546 & $\begin{array}{c}0,861 \\
61\end{array}$ & 70,91 \\
\hline 12 & $\begin{array}{c}\text { 17-Sep- } \\
19 \\
\end{array}$ & $\begin{array}{c}0,96 \\
03\end{array}$ & 0,8828 & $\begin{array}{c}0,858 \\
04\end{array}$ & 72,74 \\
\hline 13 & $\begin{array}{c}\text { 18-Sep- } \\
19 \\
\end{array}$ & $\begin{array}{c}0,96 \\
27 \\
\end{array}$ & 0,8724 & $\begin{array}{c}0,833 \\
95 \\
\end{array}$ & 70,04 \\
\hline 14 & $\begin{array}{c}\text { 19-Sep- } \\
19\end{array}$ & $\begin{array}{c}0,96 \\
28 \\
\end{array}$ & 0,8496 & $\begin{array}{c}0,853 \\
55\end{array}$ & 69,82 \\
\hline 15 & $\begin{array}{c}\text { 20-Sep- } \\
19\end{array}$ & $\begin{array}{c}0,97 \\
22\end{array}$ & 0,8961 & $\begin{array}{c}0,866 \\
38\end{array}$ & 75,48 \\
\hline 16 & $\begin{array}{c}\text { 23-Sep- } \\
19\end{array}$ & $\begin{array}{c}0,96 \\
68\end{array}$ & 0,9332 & $\begin{array}{c}0,886 \\
5\end{array}$ & 79,98 \\
\hline 17 & $\begin{array}{c}\text { 24-Sep- } \\
19\end{array}$ & $\begin{array}{c}0,97 \\
97\end{array}$ & 0,897 & $\begin{array}{c}0,886 \\
26\end{array}$ & 77,92 \\
\hline 18 & $\begin{array}{c}\text { 25-Sep- } \\
19\end{array}$ & $\begin{array}{c}0,97 \\
04\end{array}$ & 0,8512 & $\begin{array}{c}0,859 \\
74\end{array}$ & 71,02 \\
\hline 19 & $\begin{array}{c}\text { 26-Sep- } \\
19\end{array}$ & $\begin{array}{c}0,97 \\
34\end{array}$ & 0,9794 & $\begin{array}{c}0,882 \\
94\end{array}$ & 84,18 \\
\hline 20 & $\begin{array}{c}\text { 27-Sep- } \\
19 \\
\end{array}$ & $\begin{array}{c}0,97 \\
84 \\
\end{array}$ & 0,9490 & $\begin{array}{c}0,861 \\
33 \\
\end{array}$ & 79,97 \\
\hline 21 & $\begin{array}{c}\text { 30-Sep- } \\
19\end{array}$ & $\begin{array}{l}0,97 \\
688\end{array}$ & $\begin{array}{l}0,8591 \\
13777\end{array}$ & $\begin{array}{c}0,856 \\
85\end{array}$ & 71,91 \\
\hline
\end{tabular}




\subsection{Six Big Losses}

Perhitungan six big losses ini dilakukan guna untuk mengetahui faktor apa saja yang mengakibatkan rendahnya nilai OEE mesin palet pada PT. KHSTEX. Perhitungan dari six big losses sebagai berikut:

Pada bagian ini dilakukannya analisis terhadap hasil perhitungan losses. Analisis ini bertujuan agar diketahui losses manakah yang paling dominan menyebabkan rendahnya nilai OEE. Adapun perhitungan rata-rata setiap losses untuk bulan september dapat dilihat seperti pada tabel 5.2 di bawah ini.

\begin{tabular}{|c|c|c|c|c|}
\hline No & Jenis Losses & $\begin{array}{c}\text { Rata- } \\
\text { rata } \\
\mathbf{( \% )}\end{array}$ & $\begin{array}{c}\text { Persent } \\
\text { ase } \\
\mathbf{( \% )}\end{array}$ & $\begin{array}{c}\text { persentase } \\
\text { kumulatif } \\
\text { (\%) }\end{array}$ \\
\hline 1 & $\begin{array}{c}\text { Reduced } \\
\text { Speed } \\
\text { Losses }\end{array}$ & 13,79 & 45,97 & 45,97 \\
\hline 2 & $\begin{array}{c}\text { Defect } \\
\text { Losses }\end{array}$ & 11,49 & 38,31 & 84,29 \\
\hline 3 & $\begin{array}{c}\text { Equipment } \\
\text { Failure } \\
\text { Losses }\end{array}$ & 3,00 & 9,87 & 94,16 \\
\hline 4 & $\begin{array}{c}\text { Iddling and } \\
\text { Minor } \\
\text { Stopages } \\
\text { Losses }\end{array}$ & 1,20 & 4,01 & 98,16 \\
\hline 5 & $\begin{array}{c}\text { Set Up and } \\
\text { Adjustment } \\
\text { Losses }\end{array}$ & 0,55 & 1,84 & 100,00 \\
\hline 6 & $\begin{array}{c}\text { Yield/scrap } \\
\text { losses }\end{array}$ & 0,00 & 0,00 & 100,00 \\
\hline
\end{tabular}

\section{3. kaizen}

Setelah dilakukan penelusuran mengenai akar penyebab dari 2 losses dominan tersebut, selanjutnya yaitu usulan upaya perbaikan dengan pendekatan kaizen 5S.

Kedua losses dominan yaitu defect losses dan reduced speed losses memiliki beberapa akar penyebab masalah dari aspek manusia yaitu kelelahan dan keahlian yang berbeda-beda. Sehingga upaya perbaikan dengan pendekatan kaizen 5S ini ditujukan untuk menghilangkan akar penyebab masalah dari kedua losses yang dominan tersebut.

\section{KESIMPULAN}

Berdasarkan hasil perhitungan dan analisis yang telah dilakukan, maka diperoleh

kesimpulan yang sesuai dengan tujuan penelitian yaitu:

1. Dari perhitungan OEE tingkat efektivitas mesin palet menurut standart wordclass bisa dikatakan belum baik hal ini bisa dilihat dari perolehan nilai OEE dengan rata-rata persentase sebesar $71,8 \%$ dimana menurut standar word class dianggap efektif apabila berada diatas $85 \%$, artinya kinerja dari mesin palet pada bulan september belum maksimal. Dengan rendahnya nilai OEE pada mesin palet tentunya hal tersebut dapat merugikan bagi perusahaan dari segiwaktu yang tersedia, untuk itu dilakukan perhitungan six big losses. Hasilnya kerugian terbesar diakibatkan oleh reduced speed loss, dan defect losses

2. Jenis Six Big Losses yang dominan pada mesin palet yaitu defect losses dan reduced speed losses. defect losses memiliki nilai sebesar $11,49 \%$ dan persentase terhadap losses lain yaitu sebesar 84,29\%. Sedangkan reduce speed losses memiliki nilai sebesar $13,79 \%$ dan persentase terhadap losses lain sebesar 45,97\%.

3. Usulan perbaikan yang dapat dilakukan dengan pendekatan kaizen 5S yaitu:

a. Seiri (ringkas) Memisahkan material, barang, atau mesin yang masih digunakan dan yang tidak digunakan.

b. Seiton (rapi) Menata line produksi sesuai aliran proses dan menata peralatan sesuai pada tempatnya.

C. Seiso (resik)Membersihkan area kerja setiap hari setelah melakukan aktivitas produksi termasuk peralatan dan mesin yang telah digunakan.

d. Seiketsu (rawat) Menjaga kondisi area kerja yang telah rapih dan bersih setiap hari agar barang dan mesin terhindar dari kerusakan. 
e. Shitsuke (disiplin)Menetapkan aturan yang tegas terhadap segala bentuk pelanggaran yang dilakukan agar terbentuk kepribadian yang baik serta menetapkan aturan yang sesuai standar untuk karyawan dan perusahaan.

\section{DAFTAR PUSTAKA}

[1] Ariani. 2004. Pengendalian Kualitas Statistik Pendekatan Kuantitatif dan Manajemen Kualitas, Yogyakarta.

[2] Bashori, C. 2017 Analisis Penyebab Kecacatan Kain Menggunakan Metode Fault Tree Analysis (FTA) Dan Fuzzy Failure Mode And Effect Analysis (Fuzzy FMEA) Di Unit Weaving 1, Magelang.

[3] Cakrawijaya. 2008. Penerapan Budaya Kerja 5R, Jakarta.

[4] Denso. 2006. Introduction to Total Productive Maintenance (TPM) and Overall Equipment Effectiveness (OEE). Study Guide.

[5] Fahmi, A 2016. Implementasi Total Productive Maintenance Sebagai Penunjang Produktivitas Dengan Pengukuran Overall Equipment Effectiveness Pada Mesin Rotary KTH-8 (Studi Kasus PT.Indonesian Tobacco). Malang.

[6] Gesperz, V. 2002. Total Quality Management. Gramedia Pustaka Utama, Jakarta.

[7] Hiranu, Hiroyuki. 1996. Penerapan 5S Di Tempat Kerja, Jakarta.

[8] Iriani. 2013. Analisis Kegagalan Produk Integrated Circuit Dengan Menggunakan Metode FMEA di PT X, Bandung.

[9] Pandey, M. 2005. Engineering and Sustainable Development. Fault Tree Analiysis, Waterloo, University of Waterloo.

[10] Pranata. 2011. Penggunaan Metode Failure Mode and Analysis (FMEA) Untuk Mengurangi
Cacat Produk Kain Denim di PT.Garuda Mas Semesta. Universitas Widyatama, Bandung.

[11] Priyanta, Dwi. 2000. Keandalan dan Perawatan: Modul 1 Probabilitas. Surabaya, Insitut Teknologi Sepuluh November.

[12] Nakajima, S. 1988. Introduction to TPM (Total Productive maintenance) Productivity Press. Cambridge

[13]Rahman, A. 2014. Analisis Overall Equipment Effectiveness (Oee) Dalam Meminimalisi Six Big Losses Pada Mesin Produksi Dual Filters Dd07. Jurnal Tek Industri Brawijaya.

[14]Ridho, A. 2015. Analisa Penyebab Kecacatan Produk Aqua dalam Kemasan dengan Menggunakan Metode Fault Tree Analysis (FTA) dan Failure Mode dan Effect Analysis(FMEA) di PT. Tirta Investama Klaten (S1). Universitas Islam Negri Sunan Kalijaga, Yogyakarta.

[15] Rinawati, D. 2014. Analisis Penerapan Total Productive Maintenance (Tpm) Menggunakan Overall Equipment Efectiveness (Oee) Dan Six Big Losses Pada Mesin Cavitec Di Pt. Essentra Surabaya. Prosiding SNATIF Ke-1, 21-26.

[16] Stamatis. 2003. Failure mode and effect analysis. FMEA from theory to Execution, ASQ Quality Press.

[17] Tampubolon, S.V. 2008. Evaluasi Penerapan Budaya Kerja 5S di PT AKM, jakarta.

[18] Triwardani. 2013. Analisis Overall Equipment Effectiveness(OEE) dalam meminimalisi Six Big Losses pada Mesin Dual Filters DD07. Surabaya. Teknik Industri Universitas Bra Wijaya.

[19] Wahyuanti. 2014. Upaya Penurunan Produk Cacat Celana Legging Dengan Menggunakan Metode Failure Mode and Effect Analysis (FMEA) (Studi Di Whoops Bandung) Universitas Widyatama. 